\title{
Firm-Specific Foreign Exchange Exposure Identification: The Fallacy of the Stock Market Approach
}

\author{
Tom Aabo ${ }^{1} \&$ Danielle Brodin ${ }^{2}$ \\ ${ }^{1}$ Aarhus University, Aarhus, Denmark \\ ${ }^{2}$ DuPont, Copenhagen, Denmark \\ Correspondence: Tom Aabo, Aarhus University, Fuglesangs Allé 4, DK 8210 Aarhus V, Denmark.
}

Received: December 18, 2013 Accepted: December 31, 2013 Available online: January 13, 2014

doi:10.11114/aef.v1i1.304

URL: http://dx.doi.org/10.11114/aef.v1i1.304

\begin{abstract}
Previous studies have used the stock market approach to find the aggregate number of (firms with) foreign exchange exposures in a given country, region, or industry. Methodologies have differed in many aspects but two of the most basic differences relate to observation frequency and the choice of market index. Aggregate numbers have been shown to be (marginally) sensitive to the methodology employed. However, a corporate manager, an investor, or a stock analyst following a specific firm is not interested in the sensitivity on an aggregated level but on a firm-specific level. If the results for a specific firm are robust across methodologies, the corporate manager, the investor, or the stock analyst will rely on such results to a larger extent that if the results are highly sensitive to e.g. a change in observation frequency. We apply firm-specific sensitivity analysis to Scandinavian non-financial firms and find limited consistency in the detected exchange rate exposures when altering methodology in terms of observation frequency and choice of market index. The results put a question mark to the validity of the stock market approach for exchange rate exposure identification at the firm-specific level.
\end{abstract}

Keywords: exchange rate exposure, stock market approach, exposure identification, observation frequency, market index

\section{Introduction}

One of the most important prices in the international economy is the exchange rate. It simplifies the conversion of prices into different currencies. Since exchange rates can affect cash flows and stock prices of firms, the exposure to this uncertainty is a concern for investors, analysts and managers. Adler and Dumas (1984) argue that exchange rate exposure is a regression coefficient. Jorion (1990) uses this reasoning in a pioneering study explaining changes in stock prices by changes in the market index and exchange rates. This approach for foreign exchange exposure identification is called the stock market approach (Note i) and has been used repeatedly - with various modifications to the methodological set-up - by authors covering various geographic areas and timeframes (see Bartram \& Bodnar, 2007, for a survey).

The focus of these studies is to determine the percentage of firms significantly exposed to an exchange rate index or one or more bilateral exchange rates. Bodnar and Wong (2003), among others, demonstrate that this percentage is sensitive to the choice of methodological set-up. The sensitivity is measured on the aggregate level in terms of the effect of a methodological change (e.g. going from weekly to monthly data) on the percentage of significantly exposed firms. E.g. if a study identifies $30 \%$ of the firms to be significantly exposed to a change in a particular exchange rate and the same study with a different methodological setup identifies $35 \%$ of the firms to be significantly exposed, then the focus of the existing literature has been on the 5\% points difference rather than on which firms constitute the two groups. Thus, the first $30 \%$ of firms could be a perfect subset of the $35 \%$ of firms (one extreme) or there could be no overlap what so ever (the other extreme). The existing literature does not address the sensitivity under a firm-specific approach with a focus on which firms are significantly exposed to changes in exchange rates under various methodological set-ups. This is where we aim to add to the existing literature.

A primary concern of a corporate manager, an investor, or an analyst following a firm is the reliability and robustness of detected exchange rate exposures on a firm-specific level. Our specific research question is: "How sensitive is the detection of significant foreign exchange exposures at the firm-specific level to simple alterations in methodology?". In our application, we focus on two basic and simple changes in methodological set-up: 1) observation frequency and 2) 
market index. We find that the significance of exchange rate exposures at the firm-specific level is highly sensitive to these basic changes in methodological set-up. We define defection rate as the percentage of exposures that cannot be confirmed when the methodological set-up is changed. We find defections rates in the range of $73 \%$ to $89 \%$ for changes in observation frequency and defection rates in the range of $43 \%$ to $48 \%$ for changes in the market index. The high sensitivity at the firm-specific level puts a question mark to the validity of the stock market approach for detection of exchange rate exposures at the firm-specific level. We further investigate the important currencies as identified in the corporate annual reports but do not find that a particular methodological set-up (e.g. weekly as opposed to monthly observations) is superior.

Our results are based on an analysis of exchange rate exposures at the firm-specific level for large, non-financial firms in Scandinavia (Note ii) in the period 1999-2006. The Scandinavian countries are small open economies with a considerable export and import activity which makes them relevant for studies related to foreign exchange exposures. The Swedish krona (SEK) and the Norwegian krone (NOK) are freely floating while the Danish krone (DKK) is pegged to the Euro (EUR). Sweden and Denmark are members of the EU while Norway is not. This heterogeneity in terms of exchange rate regime and economic cooperation serves as a platform to verify the general character of our results.

The paper contributes to the existing literature by showing the un-reliability of the stock market approach for exchange rate exposure identification at the firm-specific level (as opposed to the aggregate level in previous studies). To the best of our knowledge this is the first paper to focus on this important issue. The paper is organized as follows. The following section reviews the literature on the use of the stock market approach for exchange rate exposure identification. Section 3 states the methodology of the study. Section 4 reports descriptive statistics and correlation coefficients. Section 5 analyzes the aggregate sensitivities to changes in methodological set-up while section 6 analyzes the firm-specific sensitivities to such changes. Section 7 concludes.

\section{Review of Literature}

Adler and Dumas (1984) argue that the traditional accounting approach is inadequate for measuring economic exposures. Instead, they propose a linear regression where the coefficient for the independent variable (in their example the French franc / U.S. dollar exchange rate) is a measure of the exposure of the dependent variable (in their example the value of a French asset measured in U.S. dollar). Jorion (1990) adopts the use of a regression coefficient as a measure of exposure and investigates the foreign exchange exposure of U.S. multinational firms. Jorion uses the following equation (Note iii):

$$
R_{i t}=\beta_{0 i}+\beta_{2 i} R_{s t}+\beta_{3 i} R_{m t}+\eta_{i t}, \quad t=1, \ldots, T,
$$

where $R_{i t}$ is the rate of return on the $i$ th firm's common stock, $R_{s t}$ is the rate of change in a trade-weighted exchange rate index, and $R_{m t}$ is the rate of return on the value-weighted market index. This basic reasoning and thus this basic equation form the backbone of subsequent studies of exchange rate exposures covering various geographic areas and timeframes.

Bartram and Bodnar (2007) provide an overview of 30 such studies covering large samples of non-financial firms. More lately the stock market approach has been used in studies by Muller and Verschoor (2006a) on European non-financial firms; Makar and Huffman (2008) on U.K. multinationals; Aggarwal and Harper (2010) on U.S. domestic non-financial firms; Bartram, Brown, and Minton (2010) on international manufacturing firms; Huffman, Makar, and Beyer (2010) on U.S. manufacturing firms; Agyei-Ampomah, Mazouz, and Yin (2012) on U.K. non-financial firms; and Al-Shboul and Anwar (in press) on Canadian non-financial firms. Authors use different methodological set-ups - e.g. monthly versus weekly data, value-weighted versus equally-weighted market indexes, local market indexes versus international market indexes, one-factor versus three-factor market models, non-orthogonalization versus orthogonalization, etc. - but the foundation is the basic reasoning and equation of Jorion (1990) as listed above.

The frequent use of the stock market approach for foreign exchange exposure identification may seem puzzling given that the risk management literature primarily focuses on the impact of exchange rates on corporate cash flows rather than the impact of exchange rates on stock prices - e.g. the financial distress motive as argued by Smith and Stulz (1985) and the underinvestment motive as argued by Froot, Scharfstein, and Stein (1993). Few studies use a cash flow approach (Note iv) but since a stock price is the discounted value of future cash flows, changes in stock prices may serve as a proxy for changes in cash flows. Bartram (2007) finds that "the impact of exchange rate risk on stock prices and cash flows is similar and determined by a related set of economic factors".

The focus of the above-mentioned studies is to determine the percentage of firms significantly exposed to an exchange rate index or bilateral exchange rates (Note v). The studies generally find that firms in more closed economies like the U.S. are less exposed to changes in foreign exchange rates than firms in more open economies e.g. in Europe (see Friberg \& Nydahl, 1999, and Muller \& Verschoor, 2006a, among others). Also generally, the empirical studies find fewer firms with significant foreign exchange exposure than theory prescribes. Bartram et al. (2010) explain this "puzzle" by showing that firms limit their actual exposures by passing through part of foreign exchange rate changes to customers and by utilizing operational and financial hedges - thus limiting the residual exposure identified by the stock market approach. 
The diversity of research methodologies in relation to the stock market approach emphasizes the need to investigate the sensitivity of exchange rate exposures to methodological choices. Bodnar and Wong (2003) demonstrate the aggregate sensitivity to changes in the market index and changes in the time horizon for measuring returns (see also Doukas, Hall, \& Lang, 2003, on the choice of time horizon and Pritamani, Shome, \& Singal, 2004, on the choice of market portfolio). However, the focus is on the aggregate level as opposed to the firm-specific level. To the best of our knowledge a large sample focus on the sensitiveness of foreign exchange rate exposures to methodological changes at the firm-specific level has not been done previously.

\section{Methodology of Study}

We investigate the exchange rate exposure of all large Scandinavian non-financial firms listed on their respective domestic stock markets. The domestic stock markets in question are Stockholm Stock Exchange, Oslo Stock Exchange and Copenhagen Stock Exchange. The Stockholm Stock Exchange and Copenhagen Stock Exchange are part of the OMX Nordic Exchange. The period investigated covers eight years, from the introduction of the Euro in January 1999 to December 2006.

The sample firms are restricted to firms that have been active and quoted on the stock exchange in question during the whole period from 1999 to 2006 . The choice of only active firms during the whole sample period may introduce survivorship bias. However, because exchange rate risk is only one (minor) risk among a range of other risk factors facing non-financial firms, it is not likely that implications from the exchange rate exposure have had a markedly connection with delisting of firms. The sample of firms is further restricted to firms with total sales of at least 100 million Euro according to the Amadeus database. The size restriction reduces the potential problem of illiquid stocks. All other information is collected from the Thompson Datastream database. The total sample consists of 157 listed Scandinavian non-financial firms (77 Swedish firms, 52 Danish firms, and 28 Norwegian firms).

We follow the reasoning of Jorion (1990) and numerous subsequent empirical studies and quantify the foreign exchange rate exposure with the following two-factor model:

$$
R_{i t}=\alpha_{i}+\beta_{M i} R_{M t}+\beta_{F X i} R_{F X t}+\varepsilon_{i t}, \quad i=1, \ldots, N \quad t=1, \ldots, T
$$

$R_{i t}$ is the rate of return (dlog) for stock $i$ at time $t ; \alpha_{i}$ is a constant; $\beta_{M i}$ is the regression coefficient which describes the market risk of stock $i ; R_{M t}$, is the rate of return (dlog) on a market portfolio; $\beta_{F X i}$ is the regression coefficient which describes the exchange rate exposure; $R_{F X t}$ is the rate of return (dlog) on the exchange rate (either an index or bilateral exchange rates) in question at time $t ; \varepsilon_{i t}$, is the random error at time t. The inclusion of the return on a market portfolio as an explanatory variable effectively makes the identified exchange rate exposure a residual or extra-market exchange rate exposure. In line with previous studies we will in the following refer to the residual exchange rate exposure as simply the exchange rate exposure.

Bodnar and Wong (2003) and Muller and Verschoor (2006b) argue that the efficient market theory implies that the exchange rate exposure should be independent of the observation frequency. The most commonly used observation frequency of the stock return data is monthly frequency (Bartram \& Bodnar, 2007) followed by weekly frequency. Few studies use quarterly or daily frequency. Iorio and Faff (2001) argue that the use of daily data is significantly stronger than the use of monthly data but Chow, Lee, and Solt (1997) argue that a longer return horizon is appropriate since daily data introduces too much noise relative to low frequency data. Bodnar and Wong (2003) find that the lengthening of the return horizon has minimal impact on the exposure estimates. In our analysis we use weekly and monthly returns. The weekly returns are calculated from Wednesday to Wednesday in order to prevent end-of-the-week-effect. To circumvent the end-of-the-month effect data from the $15^{\text {th }}$ day of each month is used (consistent with Williamson, 2001). The total number of monthly observations for each firm is 96 (8 times 12) and the corresponding number with weekly observations is 417 ( 8 times $52_{+}$).

The main aspects in relation to the choice of market index $\left(R_{M t}\right)$ are value-weighted versus equally-weighted market indexes and world market versus domestic market indexes. As it is unlikely that the market portfolio has a zero-exposure to exchange rates, the choice of which market portfolio to include in the regression impacts the magnitude and interpretation of the exposure estimates (Muller \& Verschoor, 2006b). A value-weighted portfolio is likely to be dominated by large multinational firms and is likely to resemble the portfolio of a well-diversified investor. An alternative is the use of an equally-weighted market portfolio as recommended by Bodnar and Wong (2003). We use the local equally-weighted market portfolio and alternatively the local value-weighted market portfolio (Note vi). The second important aspect regarding market portfolios is the choice between an international market portfolio and a domestic market portfolio. Chari and Henry (2004) argue that the relevant source of systematic risk for pricing stocks in a liberalized stock market should be the world stock market index as opposed to a local stock market index. Nydahl (1999) argues that a world market portfolio is more appropriate than a domestic market portfolio when the local stock market represents only a small fraction of the global market capitalization and foreign investors have full access to the local stock market (Note vii). We use local stock market indexes and alternatively the Morgan Stanley Capital 
International Europe market index, "MSCI Europe", as a proxy for an international market portfolio. The MSCI Europe market index is a value-weighted market index.

The rate of return of the exchange rate, $R_{F X t}$, is based on an index or on bilateral exchange rates. The nominal exchange rate variables in this study are the values of the Swedish, Norwegian and Danish currencies per unit of the foreign currency. Nydahl (1999) argues that using nominal exchange rates is appropriate for low inflation countries - such as the Scandinavian countries - because of the high correlation between nominal and real exchange rates. Bodnar and Gentry (1993), Amihud (1994), Choi and Prasad (1995), and Griffin and Stulz (2001) also argue that the use of real versus nominal exchange rates has a negligible effect on exposure estimates. The trade-weighted exchange rate indexes (TWI) are obtained from the Swedish, Danish and Norwegian Central Bank respectively. Bilateral exchange rates are provided by the Thompson Datastream database. The choice of bilateral exchange rates is based on the weights in the trade-weighted exchange rate index for each country. The five exchange rates with the largest weights for each country are selected (Note viii).

We investigate to which extent the firm-specific exchange rate exposure identified using the stock market approach is sensitive to changes in methodology in terms of observation frequency and choice of market index. We use two alternative observation frequencies (weekly and monthly) and three alternative market indexes (equally-weighted local market index, value-weighted local market index, and MSCI Europe). Our default set-up is to use weekly data and a local equally-weighted market index. We measure the firm-specific sensitivity to changes in methodology by calculating a defection rate. The defection rate measures the percentage of exposures that are not confirmed when alternative measures of observation frequency or market index are applied. Specifically, we have

$$
\text { Defection rate }=\left(\text { Exposures }_{\text {default }}-\left(\text { Exposures }_{\text {default }} \cap \text { Exposures }_{\text {alternative }}\right)\right) / \text { Exposures }_{\text {default }}
$$

Exposures $_{\text {default }}$ is the number of significant foreign exchange rate exposures under the default methodology. Exposures $_{\text {alternative }}$ is the number of significant foreign exchange rate exposures under the alternative methodology. By construction the defection rate is between $0 \%$ and $100 \%$ with $0 \%$ indicating a complete confirmation of detected exchange rate exposures (no sensitivity to change of methodology) and 100\% indicating no confirmation of detected exchange rate exposures (extremely high sensitivity to change of methodology). We use a 5\% significance level for the detection of exchange rate exposures.

\section{Descriptive Statistics}

Table 1 reports descriptive return statistics for trade-weighted exchange rate indexes (TWI), bilateral exchange rates, and stock indexes for the period from 1999 to 2006 for weekly observations (for the sake of brevity equivalent data based on monthly data are not reported).

Table 1. Descriptive statistics

\begin{tabular}{|c|c|c|c|c|c|}
\hline & $\mathrm{N}$ & $\begin{array}{l}\text { Average } \\
(\%)\end{array}$ & $\begin{array}{l}\text { Minimum } \\
(\%)\end{array}$ & $\begin{array}{l}\text { Maximum } \\
(\%)\end{array}$ & $\begin{array}{l}\text { Standard deviation } \\
(\%)\end{array}$ \\
\hline TWI Sweden & 417 & -0.01 & -2.86 & 2.65 & 0.74 \\
\hline TWI Denmark & 417 & 0.00 & -1.12 & 1.27 & 0.33 \\
\hline TWI Norway & 417 & -0.01 & -2.22 & 3.09 & 0.69 \\
\hline SEK per USD & 417 & -0.04 & -4.34 & 3.97 & 1.44 \\
\hline SEK per GBP & 417 & 0.00 & -3.63 & 3.13 & 1.10 \\
\hline SEK per EUR & 417 & -0.01 & -3.20 & 2.35 & 0.78 \\
\hline SEK per DKK & 417 & -0.01 & -4.38 & 2.51 & 0.83 \\
\hline DKK per USD & 417 & -0.03 & -4.79 & 4.26 & 1.37 \\
\hline DKK per GBP & 417 & 0.01 & -3.56 & 2.91 & 0.94 \\
\hline DKK per EUR & 417 & 0.00 & -0.20 & 0.17 & 0.04 \\
\hline DKK per SEK & 417 & 0.01 & -2.62 & 3.12 & 0.78 \\
\hline DKK per JPY & 417 & -0.04 & -5.84 & 8.77 & 1.57 \\
\hline NOK per USD & 417 & -0.04 & -3.85 & 4.39 & 1.41 \\
\hline NOK per EUR & 417 & -0.01 & -2.27 & 2.86 & 0.78 \\
\hline NOK per SEK & 417 & 0.00 & -3.00 & 3.49 & 0.85 \\
\hline NOK per DKK & 417 & -0.01 & -2.22 & 2.87 & 0.75 \\
\hline OMXS equal (SEK) & 417 & 0.04 & -14.16 & 8.78 & 2.92 \\
\hline OMXS value (SEK) & 417 & 0.15 & -15.47 & 12.37 & 3.23 \\
\hline OMXC equal (DKK) & 417 & 0.23 & -7.01 & 4.00 & 1.26 \\
\hline OMXC value (DKK) & 417 & 0.21 & -13.34 & 8.83 & 2.32 \\
\hline OSEAX equal (NOK) & 417 & 0.14 & -10.69 & 8.68 & 2.42 \\
\hline OSEAX value (NOK) & 417 & 0.32 & -13.15 & 9.16 & 2.72 \\
\hline MSCI Europe (EUR) & 417 & 0.04 & -12.02 & 14.05 & 2.59 \\
\hline
\end{tabular}


This table reports descriptive return statistics (dlog) using weekly data for trade-weighted exchange rate indexes (TWI), the five most important bilateral exchange rates for each country, and stock indexes for the period from the beginning of 1999 to the end of 2006. TWIs and exchange rates are obtained from the Swedish, Danish, and Norwegian central banks. $D K K=$ Danish krone, $E U R=$ Euro, $G B P=$ Great British pound, $J P Y=$ Japanese yen, $N O K=$ Norwegian krone, $S E K=$ Swedish krona, $U S D=$ U.S. dollar. The value-weighted (value) local stock indexes are obtained from Thompson Datastream. The equally-weighted (equal) local stock indexes are calculated from all the stock returns on the specific market giving equal weight to each return. $O M X S=$ Swedish stock market index ( $\mathrm{S}=$ Stockholm), $O M X C=$ Danish stock market index $(\mathrm{C}=$ Copenhagen $), O S E A X=$ Norwegian stock market index $(\mathrm{O}=\mathrm{Oslo})$. MSCI Europe is a value-weighted stock index obtained from Thompson Datastream.

Denmark experienced the least volatile trade-weighted exchange rate index (TWI) in the investigated period due to its peg to the Euro and Germany being its largest trading partner (standard deviation of $0.33 \%$ compared to $0.74 \%$ and $0.69 \%$ ). The U.S. dollar was one of the most volatile currencies towards the Scandinavian currencies (standard deviations in the range of $1.37 \%-1.44 \%$ ). The Scandinavian stock indexes outperformed the MSCI Europe index (higher average returns). All stock markets - whether national or European - with the exception of the equally-weighted Danish stock index experienced more or less the same volatility (standard deviations in the range of $2.32 \%-3.23 \%$ ).

Table 2 reports correlation coefficients for returns (dlog) using weekly data for trade-weighted exchange rate indexes (TWI), the five most important bilateral exchange rates for each country, and stock indexes. For the sake of brevity only correlation coefficients for weekly data are reported.

Table 2. Correlation coefficients

\begin{tabular}{|c|c|c|c|c|c|c|c|c|c|c|}
\hline \multicolumn{2}{|c|}{ Sweden } & \multirow{2}{*}{$\begin{array}{l}(1) \\
1.00\end{array}$} & \multirow[t]{2}{*}{ (2) } & \multirow[t]{2}{*}{ (3) } & \multirow[t]{2}{*}{ (4) } & \multirow[t]{2}{*}{ (5) } & \multirow[t]{2}{*}{ (6) } & \multirow[t]{2}{*}{ (7) } & \multirow[t]{2}{*}{ (8) } & \multirow[t]{2}{*}{ (9) } \\
\hline (1) & TWI Sweden & & & & & & & & & \\
\hline (2) & SEK per USD & 0.65 & 1.00 & & & & & & & \\
\hline (3) & SEK per GBP & 0.74 & 0.62 & 1.00 & & & & & & \\
\hline (4) & SEK per EUR & 0.89 & 0.33 & 0.51 & 1.00 & & & & & \\
\hline (5) & SEK per NOK & 0.58 & 0.33 & 0.45 & 0.51 & 1.00 & & & & \\
\hline (6) & SEK per DKK & 0.85 & 0.39 & 0.56 & 0.93 & 0.57 & 1.00 & & & \\
\hline (7) & OMXS equal (SEK) & -0.24 & -0.04 & -0.15 & -0.31 & -0.18 & -0.27 & 1.00 & & \\
\hline (8) & OMXS value (SEK) & -0.33 & -0.08 & -0.19 & -0.39 & -0.19 & -0.32 & 0.83 & 1.00 & \\
\hline (9) & MSCI Europe (EUR) & -0.35 & -0.06 & -0.22 & -0.42 & -0.19 & -0.34 & 0.73 & 0.85 & 1.00 \\
\hline \multicolumn{2}{|c|}{ Denmark } & (1) & (2) & (3) & (4) & (5) & (6) & (7) & (8) & (9) \\
\hline (1) & TWI Denmark & 1.00 & & & & & & & & \\
\hline (2) & DKK per USD & 0.84 & 1.00 & & & & & & & \\
\hline (3) & DKK per GBP & 0.73 & 0.58 & 1.00 & & & & & & \\
\hline (4) & DKK per EUR & -0.09 & -0.09 & -0.14 & 1.00 & & & & & \\
\hline (5) & DKK per SEK & 0.48 & 0.23 & 0.21 & -0.10 & 1.00 & & & & \\
\hline (6) & DKK per JPY & 0.76 & 0.63 & 0.48 & -0.11 & 0.17 & 1.00 & & & \\
\hline (7) & OMXC equal (DKK) & 0.17 & 0.07 & 0.02 & 0.06 & 0.27 & 0.11 & 1.00 & & \\
\hline (8) & OMXC value (DKK) & 0.21 & 0.12 & 0.07 & -0.01 & 0.32 & 0.09 & 0.73 & 1.00 & \\
\hline (9) & MSCI Europe (EUR) & 0.26 & 0.19 & 0.04 & 0.00 & 0.41 & 0.08 & 0.57 & 0.72 & 1.00 \\
\hline \multicolumn{2}{|c|}{ Norway } & (1) & (2) & (3) & (4) & (5) & (6) & (7) & (8) & (9) \\
\hline (1) & TWI Norway & 1.00 & & & & & & & & \\
\hline (2) & NOK per USD & 0.63 & 1.00 & & & & & & & \\
\hline (3) & NOK per GBP & 0.72 & 0.61 & 1.00 & & & & & & \\
\hline (4) & NOK per EUR & 0.84 & 0.30 & 0.48 & 1.00 & & & & & \\
\hline (5) & NOK per SEK & 0.62 & 0.24 & 0.30 & 0.47 & 1.00 & & & & \\
\hline (6) & NOK per DKK & 0.85 & 0.31 & 0.48 & 0.97 & 0.47 & 1.00 & & & \\
\hline (7) & OSEAX equal (NOK) & 0.04 & 0.08 & 0.02 & -0.09 & 0.17 & -0.09 & 1.00 & & \\
\hline (8) & OSEAX value (NOK) & -0.04 & 0.04 & -0.05 & -0.17 & 0.09 & -0.17 & 0.84 & 1.00 & \\
\hline (9) & MSCI Europe (EUR) & 0.00 & 0.10 & -0.07 & -0.17 & 0.19 & -0.16 & 0.58 & 0.65 & 1.00 \\
\hline
\end{tabular}

This table reports correlation coefficients for returns (dlog) using weekly data for trade-weighted exchange rate indexes $(T W I)$, the five most important bilateral exchange rates for each country, and stock indexes for the period from the beginning of 1999 to the end of 2006. Please refer to Table 1 for further explanation of variables. 
Table 2 shows a number of high correlation coefficients between various bilateral exchange rates. This may cause multicollinearity problems in subsequent regression analysis and is one of the arguments for the use of a trade-weighted exchange rate index (TWI). Because of the Danish krone's peg to the Euro, we remove the SEK per DKK exchange rate and the NOK per DKK exchange rate from the regression analysis as the fluctuations in these exchange rates are de facto captured by SEK and NOK per EUR. Thus, we reduce the number of bilateral exchange rates in the regression analysis for Swedish and Norwegian firms from five to four exchange rates. For all three national stock markets, Table 2 shows that the correlations between returns on the value-weighted national stock market indexes and returns on MSCI Europe exceed the correlations between returns on the equally-weighted national stock market indexes and returns on MSCI Europe. This makes intuitive sense since a value-weighted stock market index tends to be dominated by large multinational firms that are more likely to move in tandem with international markets than smaller and more domestically oriented firms.

\section{Aggregate Sensitivities}

Table 3 reports detected exposures for the 157 large Scandinavian non-financial firms for the period from the beginning of 1999 to the end of 2006 (8 years) using a 5\% significance level for exposure identification. Detected exposures are reported using weekly data (Panel A) and monthly data (Panel B). The detected exposures are the aggregate numbers of detected exposures and do not address which firms are exposed.

Table 3. Aggregate exposures and sensitivities

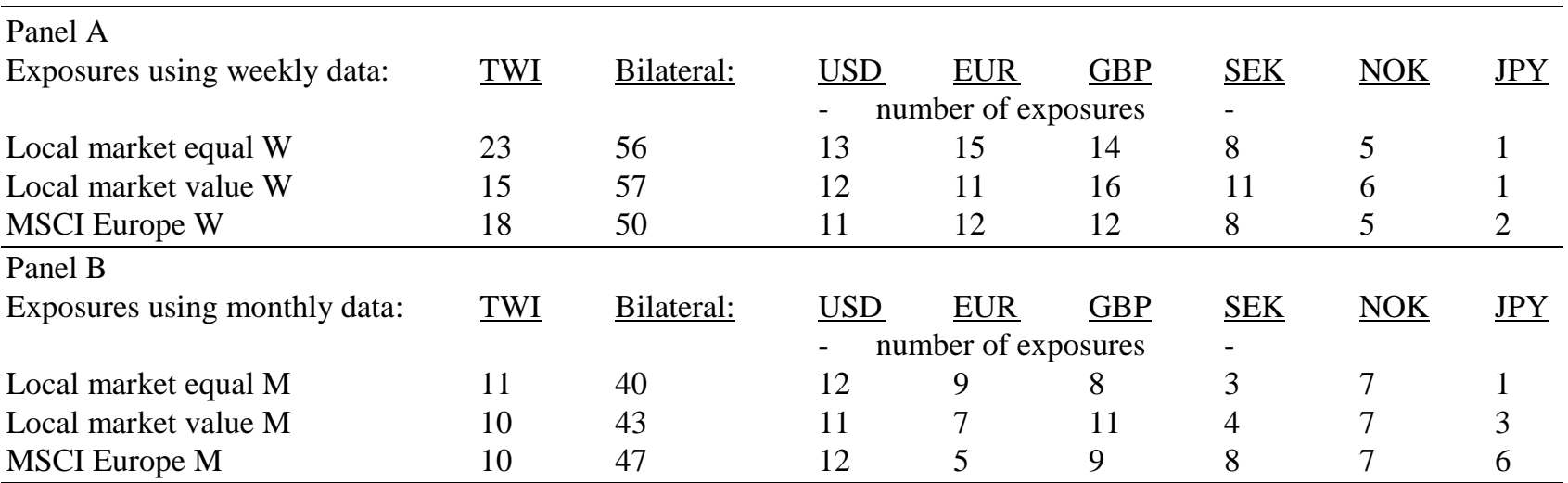

This table reports aggregate exposures for 157 large non-financial firms in Scandinavia using a 5\% significance level for exposure identification for the period from the beginning of 1999 to the end of 2006. Detected exposures are reported using weekly data (Panel A) and monthly data (Panel B). Local market refers to the Swedish, Danish, and Norwegian stock markets. Swedish / Danish / Norwegian firms are tested against the following bilateral exchange rates: USD, EUR (incl. DKK), GBP, NOK / USD, EUR, GBP, SEK, JPY / USD, EUR (incl. DKK), GBP, SEK. $W$ = weekly data, $M=$ monthly data. Please refer to Table 1 for further explanation of variables.

Table 3, Panel A, shows that the 157 sample firms have 15-23 exposures towards the trade-weighted index (TWI) and 50-57 exposures towards bilateral exchange rates depending on which market index (equally weighted, market weighted, or international) is used. Panel B, shows the exact same figures as Panel A except that the numbers are now based on monthly data. Generally, Panel B shows that the number of detected exposures is lower when we use monthly data than when we use weekly data (Note ix). The higher number of detected exchange rate exposures towards bilateral exchange rates compared to the trade-weighted index for both weekly and monthly data is in line with theoretical arguments and empirical findings in the literature (e.g. Williamson, 2001, and Muller \& Verschoor, 2006a).

The aggregate numbers in Table 3 do not tell us the firm-specific overlap. E.g. the 40 exposures that are detected in relation to bilateral exchange rates using monthly data and an equally-weighted local market index could be a perfect subset of the 56 exposures detected using weekly data (one extreme) or there could be no overlap what so ever (the other extreme). As such, Table 3 represents nothing but a replication of previous studies using Scandinavian data. The results of this replication are in line with the empirical non-US evidence or at least not surprising when considering Scandinavia as consisting of three small, open economies (e.g. Nydahl, 1999; Muller and Verschoor, 2006a; Jong et al., 2006). 


\section{Firm-specific Sensitivities}

Table 4 reports defection rates for our sample firms in relation to changes in observation frequency (Panel A) and in relation to changes in market index (Panel B) using a 5\% significance level for exposure identification for the period from the beginning of 1999 to the end of 2006. Detected exposures are reported followed by the number of exposures that is confirmed by an alternative observation frequency or alternative market indexes. Defection rate refers to the percentage of exposures that are not confirmed under the alternative methodology.

Table 4. Exposures and defection rates

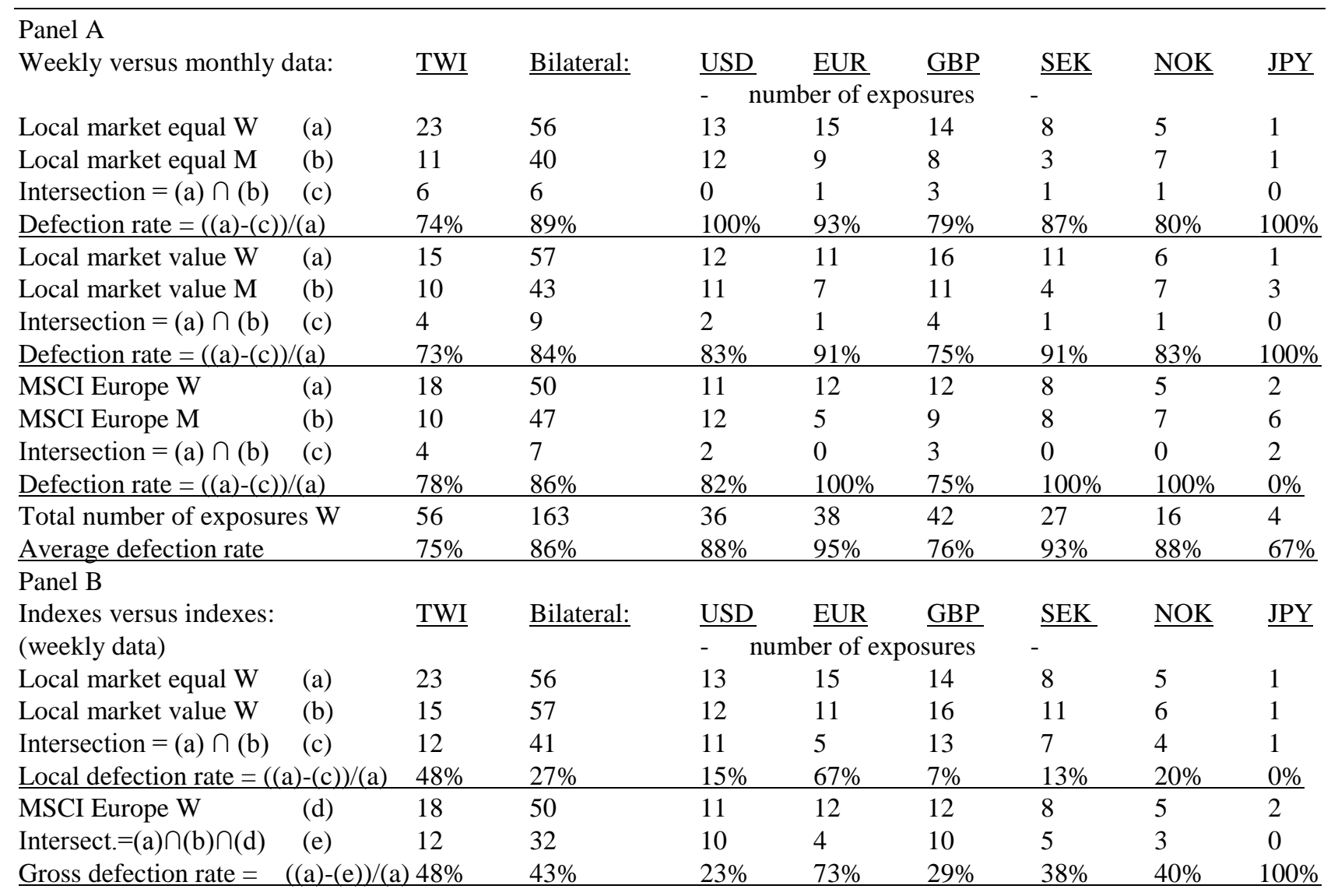

This table reports detected exposures and defection rates for 157 large non-financial firms in Scandinavia using a 5\% significance level for exposure identification for the period from the beginning of 1999 to the end of 2006. Detected exposures (Table 3) are reported followed by the number of exposures that is confirmed by (intersected with $=\cap$ ) alternative observation frequency or indexes. Panel A reports an index using weekly data confirmed by (intersected with $=\bigcap$ ) the same index using monthly data. Panel B reports an equally-weighted index using weekly data confirmed by (intersected with $=\cap$ ) other indexes using weekly data. Defection rate refers to the percentage of exposures that are not confirmed by the alternative observation frequency or index(es). Please refer to Tables 1 and 3 for further explanation of variables.

Table 4, Panel A, lists the same numbers of detected exposures for weekly and monthly data as was reported in Table 3 on the first two lines (lines 1 and 2) with the intersection between the two groups of exposures placed below these lines (line 3) followed by the corresponding defection rate (line 4). Panel A shows that detected exposures using weekly data are confirmed for only a minority of exposures when using monthly data. The average defection rate is $75 \%$ for the trade-weighted index (TWI) and $86 \%$ for bilateral exchange rates. The results highlight the need to distinguish between which firms are exposed to changes in exchange rates under various methodologies.

Table 4, Panel B, follows the same structure as Panel A but distinguishes between different market indexes as opposed to observation frequencies. The gross defection rate resembles the percentage of exposures identified using the equally-weighted local index but not confirmed by the value-weighted local index and the MSCI Europe index. The gross defection rate is $48 \%$ for the trade-weighted index (TWI) and $43 \%$ for the bilateral exchange rates. The results for Panel B using monthly data instead of weekly data are similar and for the sake of brevity not reported. 
The gross defection rates in relation to changes in the choice of market index (Panel B) are markedly lower than the average defection rates in relation to changes in observation frequency (Panel A). A defection rate of a certain size is to be expected in the case of changes in market index because 1) we are dealing with extra-market exchange rate exposures due to our use of a two-factor stock market model and 2) we cannot expect the three different market indexes to have similar exchange rate exposures. Thus, there is some economic justification for a non-zero defection rate in Panel B (change of market index) but not in Panel A (change of observation frequency).

Table 4 shows that the detection of firm-specific exchange rate exposures using the stock market approach is highly sensitive to methodological choices. In Table 5 we check the robustness of our results by investigating if our results are driven by direction (positive/negative exposures), geography (Sweden/Denmark/Norway), or time frame (1999-2002/2003-2006). We do this by replicating Table 4 for 1) only positive exposures, 2) only negative exposures, 3) only Swedish data (floating currency), 4) only Danish data (pegged currency), 5) only Norwegian data (floating currency), 6) only data for the period 1999-2002, and 7) only data for the period 2003-2006. For the sake of brevity we only report the average defection rates in relation to changes in observation frequency (Panel A) and the gross defection rates in relation to the choice of market index (Panel B). We report these defection rates for the trade-weighted index (TWI) and for bilateral exchange rates but not for the specific bilateral exchange rates. In parentheses we state the number of exposures to give a sense of the magnitude of the number of exposures under the various robustness considerations.

Table 5. Robustness of Defection Rates

\begin{tabular}{|c|c|c|c|}
\hline \multicolumn{4}{|l|}{ Panel A } \\
\hline \multicolumn{2}{|c|}{ Weekly versus monthly data: } & $\underline{T W I}$ & Bilateral exchange rates \\
\hline & & - average & ber of exposures) - \\
\hline \multicolumn{2}{|c|}{ Base case $(=$ Table 4$)$} & $75 \%(56)$ & $86 \%(163)$ \\
\hline \multirow[t]{2}{*}{ Direction: } & Positive (1) & $67 \%(37)$ & $85 \%(93)$ \\
\hline & Negative (2) & $94 \%(19)$ & $89 \%(70)$ \\
\hline \multirow[t]{3}{*}{ Geography: } & Sweden (3) & $77 \%(24)$ & $89 \%(76)$ \\
\hline & Denmark (4) & $65 \%(20)$ & $82 \%(57)$ \\
\hline & Norway (5) & $87 \%(12)$ & $87 \%(30)$ \\
\hline \multirow[t]{2}{*}{ Time frame: } & 1999-2002 (6) & $53 \%(32)$ & $72 \%(148)$ \\
\hline & 2003-2006 (7) & $85 \%(34)$ & $85 \%(171)$ \\
\hline \multicolumn{4}{|l|}{ Panel B } \\
\hline \multicolumn{2}{|c|}{ Indexes versus indexes: } & TWI & Bilateral exchange rates \\
\hline & & \multicolumn{2}{|c|}{ - gross defection rates (number of exposures) - } \\
\hline \multicolumn{2}{|c|}{ Base case $(=$ Table 4$)$} & $48 \%(23)$ & $43 \%(56)$ \\
\hline \multirow[t]{2}{*}{ Direction: } & Positive (1) & $18 \%(11)$ & $29 \%(28)$ \\
\hline & Negative (2) & $75 \%(12)$ & $57 \%(28)$ \\
\hline \multirow[t]{3}{*}{ Geography: } & Sweden (3) & $70 \%(10)$ & $53 \%(30)$ \\
\hline & Denmark (4) & $25 \%(8)$ & $39 \%(18)$ \\
\hline & Norway (5) & $40 \%(5)$ & $13 \%(8)$ \\
\hline \multirow[t]{2}{*}{ Time frame: } & 1999-2002 (6) & $69 \%(13)$ & $49 \%(49)$ \\
\hline & 2003-2006 (7) & $73 \%(15)$ & $51 \%(59)$ \\
\hline
\end{tabular}

This table is a robustness test of Table 4 and reports defection rates and total number of exposures under alternative restrictions (positive/negative, Sweden/Denmark/Norway, 1999-2002, and 2003-2006). Panel A reports average defection rates for an index using weekly data confirmed by (intersected with $=\cap$ ) the same index using monthly data. Panel B reports gross defection rates for an equally-weighted local index using weekly data confirmed by (intersected with $=\cap$ ) other indexes using weekly data. Please refer to Table 4 for details.

The first line of Table 5, Panel A, is a summary of Table 4 in terms of the average defection rate $(75 \%$ and $86 \%)$ and the total number of exposures (56 and 163, Note x) for the traded-weighted index (TWI) and the bilateral exchange rates respectively. The following lines show the average defection rates (and the number of exposures) under alternative methodologies. First, we divide our detected exposures in terms of direction $(1+2)$. Second, we divide our detected exposures in terms of geography $(3+4+5)$. In these two instances we simply divide our detected exposures in the base case into smaller groups based on either direction or geography. Third, we divide our time period into halves $(6+7)$. Panel B (change in market index) follows the exact some structure as Panel A (change in observation frequency).

Table 5 indicates that our main results are general and not unduly driven by specific "outliers" in terms of direction, geography, or time frame. This is especially true for the choice of observation frequency. Thus, for changes in observation frequency the $75 \%$ average defection rate (Table 4) for the trade-weighted index (TWI) is bounded by 53\% 
and $94 \%$ (Table 5) and the $86 \%$ average defection rate (Table 4) for bilateral exchange rates is bounded by $72 \%$ and $89 \%$ (Table 5).

We exploit information in the annual reports of the firms to get a rough estimate of the potential superiority of one methodology versus an alternative methodology in relation to bilateral exchange rates. We use two main pieces of information from the annual reports to get an indication of the relevant firm-specific exchange rate exposures: 1) Exchange rates with the largest impact specified by the firm in the risk management section and 2) the geographical sales distribution. Specifically, we hand-collect annual reports from the last year of the period investigated (2006 or 2006/7) for our sample firms and identify up to five major exchange rates for each firm based on the two criteria above. Ihrig (2001) creates firm-specific exchange rates based on a weighted average of the local currencies of the firm's foreign subsidiaries. Jong et al. (2006) ask all firms in a questionnaire to indicate up to three exchange rates that have the most influence on firm value and validate these responses by using annual report data in the form of the geographical sales distribution. They find a significant correlation between the geographical sales distribution and the results of the questionnaire.

We identify an average of 3.8 exchange rates for each firm. The identified exchange rates are not restricted to the exchange rates used in our analysis. On average 1.0 exchange rate for each firm is not an exchange rate covered in our previous analysis. In approximate terms, we can say that the average firm in our sample is exposed to four exchange rates (based on information in the annual reports) of which three exchange rates are covered in our previous analysis. This is comforting in the sense that although our previous analysis uses a standard set of exchange rates it does cover the major part of relevant exchange rates for our sample firms.

Table 6 shows exposures, hits and hit ratios for bilateral exchange rates for each model set-up (weekly data in Panel A and monthly data in Panel B). The exposures are the exposures reported in Table 3 under the heading "Bilateral" and later used in Table 4. Hits are the number of the before-mentioned exposures that can be confirmed by the identification of important exchange rates through information in the annual reports as outlined above. Finally, hit ratio is the number of hits divided by the number of exposures.

Table 6. Hit Rates

\begin{tabular}{llll}
\hline Panel A & Exposures & $\underline{\text { Hits }}$ & $\underline{\text { Hit ratio }}$ \\
Bilateral exchange rates (weekly data): & 56 & 38 & $68 \%$ \\
Local market equal W & 57 & 33 & $58 \%$ \\
Local market value W & 50 & 33 & $66 \%$ \\
MSCI Europe W & 54 & 35 & $64 \%$ \\
Average & Exposures & $\underline{\text { Hits }}$ & $\underline{\text { Hit ratio }}$ \\
\hline Panel B & 40 & 33 & $83 \%$ \\
Bilateral exchange rates (monthly data): & 43 & 33 & $72 \%$ \\
Local market equal M & 47 & 32 & $70 \%$ \\
Local market value M & 43 & & $75 \%$ \\
MSCI Europe M & & & \\
Average & &
\end{tabular}

This table reports exposures, hits, and hit ratios for bilateral exchange rates for each model set-up with models using weekly data shown in Panel A and models using monthly data shown in Panel B. The exposures are the exposures reported in Table 3 under the heading "Bilateral". Hits are the number of exposures that can be confirmed by the identification of important exchange rates through information in the annual reports (exchange rates with the largest impact according to the risk management section and/or the geographical sales distribution). Hit ratio is the number of hits divided by the number of exposures. Please refer to Table 3 for further explanation of variables.

Table 6 does not single out a superior model set-up. The use of monthly data does seem to imply a larger hit ratio but this is based on a lower number of detected exposures. No model set-up seems to be markedly superior to alternative model set-ups - at least within the range of model set-ups that we investigate. It may seem surprising to find fairly high hit ratios. This does signify some kind of success in using the stock market approach for exchange rate exposure identification. However, the stock market approach identifies less than one significant exchange rate per firm. This is in contrast to almost four identified exchange rates in the annual reports. Based on this difference in magnitude of the numbers of identified exposures, it is no surprise that the hit ratios are fairly high despite the fact that we find that there is limited consistency in the exchange rates identified through the stock market approach under different methodologies. 


\section{Conclusions}

Based on a sample of 157 listed, non-financial firms in Scandinavia and using a traditional two-factor stock market model for exchange rate exposure identification, we find that the exchange rate exposures identified for the specific firm is highly sensitive to simple alterations in the methodology of the study (change of observation frequency and change of market index). Further analysis based on firm-specific information in the annual reports on exchange rate exposures does not indicate a superior methodology. The high sensitivity is not driven by a specific direction, geographical area, or time period but seems to be of a more general character. For a corporate manager, an investor, or a stock analyst interested in the exchange rate exposures of a specific firm, the findings of this study put a question mark to the validity of the stock market approach for exchange rate exposure identification at the firm-specific level.

Our findings are based on a broad set of large, non-financial firms in Scandinavia. Scandinavia consists of three small, open economies and compared to other more closed economies, we cannot expect to be able to transfer our findings in relation to the aggregate number of detected exposures. But on our main focus point - the reliability of detected exchange rate exposures for a given firm - we see no reason why this should be a particular Scandinavian phenomenon.

\section{Acknowledgements}

We thank participants at the Annual Conference of the Multinational Finance Society, the European Financial Management Annual Meeting, the Infinity Conference on International Finance, and the Southern Finance Association Annual Meeting for helpful comments and suggestions. We appreciate research assistance from Carsten Vinther.

\section{References}

Adler, M., \& Dumas, B. (1984). Exposure to currency risks: Definition and measurement. Financial Management, 13, 41-50. http://dx.doi.org/10.2307/3665446

Aggarwal, R., \& Harper, J.T. (2010). Foreign exchange exposure of "domestic" corporations. Journal of International Money and Finance, 29, 1619-1636. http://dx.doi.org/10.1016/j.jimonfin.2010.05.003

Agyei-Ampomah, S., Mazouz, K., \& Yin, S. (2012). The foreign exchange exposure of UK non-financial firms: A comparison of market-based methodologies. International Review of Financial Analysis, 29, 251-260. http://dx.doi.org/10.1016/j.irfa.2012.05.006

Al-Shboul, M. \& Anwar, S. (2014). Foreign Exchange Rate Exposure: Evidence from Canada. Review of Financial Economics, forthcoming. http://dx.doi.org/10.1016/j.rfe.2013.12.001

Amihud, Y. (1994). Exchange Rates and the Valuation of Equity Shares. In: Y. Amihud \& R. Levich (Eds.), Exchange Rates and Corporate Performance (pp. 49-59). Business One Irwin.

Bartram, S. M., Brown, G. W, \& Minton, B. A. (2010). Resolving the Exposure Puzzle: The Many Facets of Exchange Rate Exposure. Journal of Financial Economics, 95, 148-173. http://dx.doi.org/10.1016/j.jfineco.2009.09.002

Bartram, S.M. (2007). Corporate cash flow and stock price exposures to foreign exchange risk. Journal of Corporate Finance, 13, 981-994. http://dx.doi.org/10.1016/j.jcorpfin.2007.05.002

Bartram, S.M., \& Bodnar, G.M. (2007). The exchange rate exposure puzzle. Managerial Finance, 33, 642-666. http://dx.doi.org/10.1108/03074350710776226

Bodnar, G. M., \& Gentry, W. M. (1993). Exchange Rate Exposure and Industry Characteristics: Evidence from Canada, Japan and the USA. Journal of International Money and Finance, 12, 29-45. http://dx.doi.org/10.1016/0261-5606(93)90008-Y

Bodnar, G. M., \& Wong, F. (2003). Estimating Exchange Rate Exposure: Issues in Model Structure. Financial Management, 32, 35-67. http://dx.doi.org/10.2307/3666203

Brown, G.W. (2001). Managing foreign exchange risk with derivatives. Journal of Financial Economics, 60, 401-448. http://dx.doi.org/10.1016/S0304-405X(01)00049-6

Chari, A., \& Henry, P.B. (2004). Risk Sharing and Asset Prices: Evidence from a Natural Experiment. Journal of Finance, 59, 1295-1324. http://dx.doi.org/10.1111/j.1540-6261.2004.00663.x

Choi, J. J., \& Prasad, A. M. (1995). Exchange Risk Sensitivity and Its Determinants: A Firm and Industry Analysis of U.S. Multinationals. Financial Management, 24, 77-88. http://dx.doi.org/10.2307/3665559

Chow, E. H., Lee, W. Y., \& Solt, M. E. (1997). The Exchange-Rate Risk Exposure of Asset Return. The Journal of Business, 70, 105-123. http://dx.doi.org/10.1086/209710

Doukas, J. A., Hall, P. H., \& Lang, L. H. P. (2003). Exchange Rate exposure at the Firm and Industry Level. Financial Markets, Institutions \& Instruments, 12, 291-346. http://dx.doi.org/10.1046/j.0963-8008.2003.00001.x 
Friberg, R., \& Nydahl, S. (1999). Openness and the Exchange Rate Exposure of National Stock Markets. International $\begin{array}{lllll}\text { Journal of } & \text { Finance }\end{array}$ http://dx.doi.org/10.1002/(SICI)1099-1158(199901)4:1<55::AID-IJFE90>3.0.CO;2-1

Froot, K.A., Scharfstein, D.S., \& Stein, J.C. (1993). Risk management: coordinating corporate investment and financing policies. Journal of Finance, 48, 1629-1658. http://dx.doi.org/10.2307/2329062

Garner, C.K., \& Shapiro, A.C. (1984). A practical method of assessing foreign exchange risk. Midland Corporate Finance Journal, 2, 6-17.

Griffin, J. M., \& Stulz, R. M. (2001). International Competition and Exchange Rate Shocks: A Cross-Country Analysis of Stock Returns. The Review of Financial Studies, 14, 215-241. http://dx.doi.org/10.1093/rfs/14.1.215

Huffman, S.P., \& Makar, S.D., Beyer, S.B. (2010). A three-factor model investigation of foreign exchange-rate exposure. Global Finance Journal, 21, 1-12. http://dx.doi.org/10.1016/j.gfj.2010.03.004

Ihrig, J. (2001). Exchange Rate Exposure of Multinationals: Focusing on Exchange Rate Issues. Board of Governors of the Federal Reserve System - International Finance Discussion Papers, Number 709. http://dx.doi.org/10.2139/ssrn.282569

Iorio, A. D., \& Faff, R. (2001). A test of the stability of exchange rate risk: Evidence from the Australian equities market. Global Finance Journal, 12, 179-203. http://dx.doi.org/10.1016/S1044-0283(01)00027-8

Jong, A. D., Ligterink, J., \& Macrae, V. (2006). A Firm-Specific Analysis of the Exchange-Rate Exposure of Dutch Firms. Journal of International Financial Management and Accounting, 17, 1-28. http://dx.doi.org/10.1111/j.1467-646X.2006.00119.x

Jorion, P. (1990). The exchange-rate exposures of U.S. multinationals. Journal of Business, 63, 331-345. http://dx.doi.org/10.1086/296510

Makar, S.D., \& Huffman, S.P. (2008). UK Multinationals' Effective Use of Financial Currency-Hedge Techniques: Estimating and Explaining Foreign Exchange Exposure Using Bilateral Exchange Rates. Journal of International Financial Management and Accounting, 19, 219-235. http://dx.doi.org/10.1111/j.1467-646X.2008.01022.x

Marston, R.C. (2001). The effects of industry structure on economic exposure. Journal of International Money and Finance, 20, 149-164. http://dx.doi.org/10.1016/S0261-5606(00)00052-8

Muller, A., \& Verschoor, W. F. C. (2006a). European Foreign Exchange Risk Exposure. European Financial Management, 12, 195-220. http://dx.doi.org/10.1111/j.1354-7798.2006.00316.x

Muller, A., \& Verschoor, W. F. C. (2006b). Foreign Exchange Risk Exposure: Survey and Suggestions. Journal of Multinational Financial Management, 16, 385-410. http://dx.doi.org/10.1016/j.mulfin.2005.09.001

Nydahl, S. (1999). Exchange Rate Exposure, Foreign Involvement and Currency Hedging of Firms: Some Swedish Evidence. European Financial Management, 5, 241-257. http://dx.doi.org/10.1111/1468-036X.00091

Oxelheim, L., \& Wihlborg, C.G. (1995). Measuring macroeconomic exposure: the case of Volvo cars. European Financial Management, 1, 241-263. http://dx.doi.org/10.1111/j.1468-036X.1995.tb00019.x

Pritamani, M. D., Shome, D. K., \& Singal, V. (2004). Foreign Exchange Exposure of Exporting and Importing Firms. Journal of Banking \& Finance, 28, 1697-1710. http://dx.doi.org/10.1016/j.jbankfin.2003.06.002

Smith, C.W., \& Stulz, R.M. (1985). The determinants of firms' hedging policies. Journal of Financial and Quantitative Analysis, 20, 391-405. http://dx.doi.org/10.2307/2330757

Williamson, R. G. (2001). Exchange Rate Exposure and Competition: Evidence from the Automotive Industry. Journal of Financial Economics, 59, 441-475. http://dx.doi.org/10.1016/S0304-405X(00)00093-3

Note ${ }^{i}$. The stock market approach is generally applied using a two-factor stock market model where a market index serves as an independent variable. This procedure effectively makes the exchange rate coefficient an indicator of an extra-market exchange rate exposure. We will in the following refer to the two-factor stock market model as the stock market model.

Note ${ }^{\text {ii. }}$ Scandinavia is defined as Sweden, Norway, and Denmark. Some definitions of Scandinavia include Iceland and Finland. We use the narrow definition of Scandinavia in accordance with e.g. Encyclopaedia Britannica. 
Note ${ }^{\text {iii. }}$. Initially in the paper, Jorion (1990) suggests an equation that excludes the market index $\left(R_{i t}=\beta_{0 i}+\beta_{l i} R_{s t}+\varepsilon_{i t}\right)$ but preferring to explicitly control for market movements and noting that the coefficients of exchange rate exposure estimated by the two equations are highly correlated (a rank correlation of 0.968 ), Jorion focuses on the market-adjusted betas in his further analysis.

Note ${ }^{\text {iv }}$. For examples of the very scarce use of the cash flow approach for exchange rate exposure identification please refer to Garner and Shapiro (1984), Oxelheim and Wihlborg (1995), and Brown (2001). All these studies are restricted to the analysis of a single firm.

Note $^{\mathrm{v}}$. For a discussion on the choice between an exchange rate index versus bilateral exchange rates see e.g. Jong, Ligterink, and Macrae (2006).

Note ${ }^{\text {vi }}$. The value-weighted index data is obtained from Thompson Datastream. The equally-weighted index data is calculated from collecting data for all stock prices on the market in question and thereafter computing the returns, both on a weekly and a monthly basis. The stocks are given an equal weight in the calculation of the market return.

Note ${ }^{\text {vii }}$. This justifies to some extent why U.S. studies tend to use the domestic market index since the U.S. market constitutes a large fraction of the global market.

Note viii. The main trading partners of Sweden are Germany (22\%), the U.S. (12\%), the U.K. (12\%), France (7\%), Finland (7\%), Italy (6\%), Denmark (6\%), and Norway 6\%) leading to EUR, USD, GBP, DKK and NOK being the most significant currencies (Germany, France, Finland and Italy have all adopted the Euro). The main trading partners of Norway are Sweden (20\%), Germany (15\%), the U.K. (12\%), Denmark (8\%), and the U.S. (7\%) leading to SEK, EUR, GBP, DKK and USD being the most significant currencies. The main trading partners of Denmark are Germany $(21 \%)$, the U.K. (10\%), Sweden (9\%), the U.S. (9\%), France (7\%), Netherlands (5\%), Italy (5\%), Belgium (4\%) and Japan (4\%) leading to EUR, GBP, SEK, USD, and JPY being the most significant currencies (Germany, France, Netherlands, Italy, and Belgium have all adopted the Euro).

Note ${ }^{\text {ix }}$. This is in line with Jong et al. (2006) who find 21 Dutch firms exposed to a trade-weighted index when using a $5 \%$ significance level and weekly data but only 14 firms when using monthly data.

Note ${ }^{x}$. The number of exposures (163) exceeds the number of firms (157) in the case of bilateral exchange rates because some firms are exposed to more than one bilateral exchange rate.

\section{$(\mathrm{cc}) \mathrm{BY}$}

This work is licensed under a Creative Commons Attribution 3.0 License. 